\title{
Uma proposta de gamificação do processo avaliativo no ensino de física em um curso de licenciatura
}

Vinicius Munhoz Fraga ${ }^{1}$

Maria Cristina do Amaral Moreira ${ }^{1}$

Marcus Vinicius Pereira ${ }^{l}$

Instituto Federal de Educação, Ciência e Tecnologia do Rio de Janeiro

Rio de Janeiro - RJ

\section{Resumo}

O presente artigo apresenta uma experiência de combinação entre uma metodologia passiva, caracterizada por aulas expositivas ministradas pelo professor, e uma ativa, baseada na gamificação aplicada ao processo avaliativo de uma disciplina de Física em um curso de Licenciatura em Química. Os alunos foram divididos em quatro equipes $e$ realizaram atividades individuais (frequência, pontualidade, participação nas aulas, etc.), coletivas (seminários em equipe, resolução de listas de exercícios, atividades experimentais) e competitivas (desafios entre equipes), que compunham o processo avaliativo a ser culminado na prova escrita. Essas atividades eram recompensadas com moedas do jogo denominadas teslas, que foram utilizadas no mercado, ambiente da gamificação onde seria possível adquirir itens capazes de alterar a estrutura de valor da prova, possibilitando ao aluno escolher uma estratégia particular e personalizada para resolver sua avaliação de acordo com seu desenvolvimento na disciplina. A coleta de dados foi realizada por meio de questionário aberto visando identificar e analisar os pontos positivos e negativos destacados pelos alunos. Como resultado, foram identificados incremento do engajamento e da motivação dos discentes que demonstraram aumento de interesse nas aulas e no compromisso com a disciplina, além de, como futuros

\footnotetext{
${ }^{+}$A proposal for gamification of the evaluation process in the physics teaching in an initial teacher education course

* Recebido: março de 2020. Aceito: julho de 2020.

${ }^{1}$ E-mails: vinicius.fraga@ifrj.edu.br; maria.amaral@ifrj.edu.br; marcus.pereira@ifrj.edu.br
} 
professores, reconhecerem a gamificação como estratégia inovadora, porém igualmente trabalhosa, pois demanda planejamento adequado.

Palavras-chave: Ensino de Física; Metodologia Ativa; Gamificação; Engajamento; Motivação.

\begin{abstract}
The present work presents an experience of combining a passive and an active methodology - gamification - applied to the evaluation process of a Physics discipline in a Chemistry Degree Teacher Education course. Students were divided into four teams and carried out individual activities (frequencies, punctuality, participation in classes etc.), and collective activities (team seminars, solving exercises list, experimental activities) and competitive activities (team challenges), which comprised the evaluation process to be culminated in the written test. These activities were rewarded with game coins called teslas, which were used in the market, a gamification environment where it would be possible to purchase items capable of altering the value structure of the test, allowing the student to choose a particular and personalized strategy to resolve his evaluation accordingly with its development in the discipline. Data collection was conducted using an open questionnaire to identify, investigate and analyze the positive and negative points highlighted by the students. As a result, an increase in the engagement and motivation of the students was identified, which showed an increase in interest in classes and in the commitment to the discipline, in addition to, as future teachers, recognizing gamification as an innovative strategy, but equally laborious, as it requires adequate planning.
\end{abstract}

Keywords: Physics Education; Active Methodology; Gamification; Engagement; Motivation.

\title{
I. Introdução
}

Quando se trata de ensino, a metodologia tem papel fundamental no tocante à formação dos alunos. Podemos categorizar as metodologias de ensino em passivas, quando o aluno tem papel de receptor do conhecimento, e ativas, quando o aluno assume protagonismo nas atividades que envolvem a construção do seu próprio conhecimento. Atualmente, as metodologias passivas, geralmente de caráter expositivo e sem a devida problematização, acabam privilegiando a memorização e a busca por informações prontas. Quanto ao 
desenvolvimento do engajamento e da motivação, os alunos não são estimulados a participarem ativamente do seu processo de aprendizagem em detrimento de algumas competências como originalidade, autonomia e criatividade.

Entendendo que a aplicação de metodologias ativas de maneira eficaz necessita ocorrer paralelamente a fatores como formação inicial continuada, apoio da gestão escolar, entendimento da mudança de papel do professor e do aluno, planejamento adequado, dentre outros, surge a pergunta: como desenvolver uma metodologia ativa de maneira a proporcionar engajamento e motivação em um sistema educacional em que predominam as metodologias passivas? $\mathrm{Na}$ tentativa de encontrar resposta a essa pergunta, desenvolveu-se uma proposta de combinação entre duas metodologias: a metodologia passiva de aulas tradicionais, ministradas de forma expositiva, com a metodologia ativa da gamificação, aplicada ao processo avaliativo. Tem-se como objetivo pedagógico apresentar uma proposta de gamificação do processo avaliativo dos alunos de maneira a estimular o engajamento e aumentar sua motivação.

\section{Referencial Teórico}

Quando o olhar é voltado para o cenário educacional atual, é notório que a aprendizagem por recepção, aquela em que o objeto de aprendizagem é apresentado em sua forma final, prevalece em relação à por descoberta, aquela em que o objeto de aprendizagem é descoberto pelo estudante (MOREIRA; MASINI, 2006). A problemática não está diretamente relacionada ao processo utilizado, mas ao produto dele, isto é, se a aprendizagem gerada é significativa. Nesse sentido, para Bacich e Moran $(2018$, p. 4) as "metodologias ativas são estratégias de ensino centradas na participação efetiva dos estudantes na construção do processo de aprendizagem, de forma flexível, interligada e híbrida".

Apesar dos estudos sobre metodologias ativas serem amplamente desenvolvidos na literatura (MATTAR, 2017; BACICH; MORAN, 2018; CAMARGO; DAROS, 2018), não se pode afirmar o mesmo sobre sua implementação nas salas de aula, uma vez que as metodologias passivas ainda são a principal abordagem metodológica utilizada nas escolas (FAVA, 2014; JARAUTA; IMBERNÓN, 2015; CARMARGO; DAROS, 2018). As instituições de ensino, atentas às mudanças, partem essencialmente por dois caminhos: ou mantêm o modelo curricular predominantemente disciplinar e solicita maior envolvimento do estudante, fazendo uso, por exemplo, do ensino híbrido (blended learning) e a sala de aula invertida (flipped classroom); ou propõem modelos "inovadores, disruptivos, sem disciplinas, que redesenham o projeto, os espaços físicos, as metodologias, [...] cada aluno aprende no seu próprio ritmo e necessidade" (MORAN, 2015, p. 15).

A relação entre o aluno do século XXI e a forma como ocorre seu aprendizado já não se desenvolve de forma eficiente por meio apenas de uma metodologia passiva focada em uma aprendizagem por transmissão. É preciso que o estudante se perceba no processo, se torne protagonista. Aprendemos aquilo que nos interessa e só nos interessa aquilo do que 
fazemos parte (MOREIRA; MASINI, 2006), e justamente aí surge a gamificação (gamification), que consiste na inserção de elementos de jogos em atividades educativas a fim de torná-las mais divertidas e engajadoras. Segundo Kapp, Blair e Mesch (2014, p. 7), a gamificação consiste na "utilização de mecânica, estética e pensamentos baseados em games para engajar pessoas, motivar a ação, promover a aprendizagem e resolver problemas".

Gamificar, experimentar, trabalhar com situações reais, aprender de forma colaborativa, tudo isso faz mais sentido para os alunos da atual geração, visto que são características que contemplam competências exigidas aos indivíduos do século XXI (BURKE, 2015). Nesse sentido, visando a promoção da aprendizagem, a gamificação ganha destaque, visto que acrescenta uma nova camada de interesse ao aprendizado ao inserir o lúdico no processo educacional (ALVES, 2015). Quanto às competências do século XXI, estudos relacionados à gamificação consideram engajamento e motivação como soluções eficientes para a aprendizagem dos alunos:

A resolução de problemas se intensifica por meio dos games por sua natureza cooperativa e, por vezes, competitiva. Aceitamos as regras do jogo, sabemos qual é a meta, concordamos em jogar com pessoas diferentes para alcançarmos os objetivos e aceitamos feedback corretivo para o alcance do resultado desejado. Some a isso os aspectos do desafio e o prazer de participar da construção de algo de maneira voluntária e você terá um grande volume de problemas resolvidos com muito mais inovação e eficácia (ALVES, 2015, p. 28).

Por essas características, a gamificação, pode se configurar como uma metodologia eficaz para se desenvolver o processo de ensino e aprendizagem dos alunos.

\section{Percurso Metodológico}

\section{III.1 Metodologia da Pesquisa}

Esse artigo foi desenvolvido em uma abordagem qualitativa e teve como metodologia de análise de dados a Análise de Livre Interpretação - ALI que segundo Anjos, Rôças e Pereira (2019) chancela a interpretação do professor-pesquisador por meio da combinação entre suas observações e experiencias profissionais com o referencial teórico de sua pesquisa. A ALI não deve ser entendida como uma análise superficial de dados, visto que sua proposta

não se esvazia nos "achismos" de uma observação rasa, mas que ocorre dentro de um repertório que não cessa em criatividade, sob um referencial teórico e desenho metodológico de uma pesquisa de cunho qualitativo, reforçados pelo estudo e nas sensibilidades advindas do olhar diferenciado para o campo de pesquisa vivido por muitos professores-pesquisadores (ANJOS; RÔÇAS; PEREIRA, 2019, p. 3). 
mas sim como uma metodologia de análise que vai além de dispositivos analíticos de pesquisa ao permitir que o professor-pesquisador considere sua análise interpretativa, constituída na combinação entre sua observação e a teoria.

A ALI vai ser somada ao conhecimento em que se aportou o professor-pesquisador, na experiência pessoal de cada sujeito envolvido na pesquisa, nas relações que dispõem canais verbais e não verbais, como forma de interações que comungam compreensão e captação dos contextos circundantes e comunicativos. Esses são constitutivos de uma autorização ao pensamento expresso nos pressupostos e de tudo mais que o acompanha como análise - reflexão, intuição, razão, emoção, elaboração, leituras e concepções de realidade - bem como as significações das falas e dados que remetem ao passaporte e à autenticidade no fazer da pesquisa (ANJOS; RÔÇAS; PEREIRA, 2019, p. 6).

Os participantes da pesquisa foram um grupo de quinze alunos inscritos na disciplina Física Geral III ofertada em um curso de Licenciatura em Química de um Instituto Federal. A disciplina teve dezoito encontros compostos cada um por seis aulas de 50 minutos (5h por encontro), em que todo o conteúdo programático foi trabalhado por meio de aulas expositivas que utilizavam como recurso didático o quadro branco e apresentações em slides via datashow construídas utilizando recursos de imagens estáticas e animadas, vídeos e simulações de computador que contribuíssem para minimizar o nível de abstração dos tópicos abordados, relacionados à eletricidade e magnetismo. A maneira como as aulas foram estruturadas caracteriza o processo didático do docente por meio de uma metodologia passiva.

Quanto ao processo de avaliação, nossa proposta foi combinar a avaliação somativa com a formativa. O processo de gamificação proposto, que será desenvolvido na subseção seguinte, tinha como foco acompanhar a evolução do aluno no decorrer do semestre letivo com intuito de melhorar o processo de ensino-aprendizagem a partir do incremento de seu engajamento e motivação. Cada atividade era considerada uma avaliação, as tarefas concluídas serviam de apoio as seguintes e os alunos podiam acompanhar sua evolução encontro após encontro, por isso, caracterizamos esse processo contínuo como avaliação formativa (PERRENOUD, 1999). Entretanto, como uma prova escrita foi aplicada em dois momentos (na metade e no final do semestre) visando determinar o grau do domínio acerca do conteúdo desenvolvido no semestre e atribuindo consequentemente uma nota ao aluno (exigência da instituição), entendemos que mesmo com os diferenciais apresentados na proposta de gamificação o processo avaliativo tem, mesmo que em parte, um caráter somativo (BLOOM, 1983).

\section{III.2 Metodologia de Ensino}

A proposta de gamificação foi projetada com base nas técnicas de motivação apresentadas por John Keller em seu modelo de quatro fatores ARCS - Atenção, Relevância, Confiança e Satisfação (KELLER, 2010). Apesar de originalmente esse modelo ter foco no 
design instrucional, termo relativo ao conjunto de métodos e técnicas utilizadas em processos de ensino-aprendizagem, pode ser aplicado também a gamificação (ALVES, 2015).

No primeiro encontro da disciplina foi apresentado aos estudantes como metodologia seria aplicada ao processo avaliativo e não o processo didático (as aulas em si). Eles escolheram uma imagem para ser usada como seu avatar (referência do jogador dentro de um ambiente de jogo). A turma foi dividida em quatro equipes de maneira que as atividades cooperativas e competitivas a serem propostas não comprometessem o nível de dificuldade devido à diferença entre o número de integrantes por equipe. As equipes foram nomeadas em homenagem a: Ampère, Faraday, Franklin e Gauss. Cada estudante recebeu um cartão digital contendo seu nome, nome da equipe, nome do professor, semestre letivo, a imagem de seu avatar e um código bidimensional ( $Q R$ Code) que levaria o aluno a uma planilha de pontuação. Os cartões digitais eram individuais e seguiam o modelo conforme a Fig. 1.

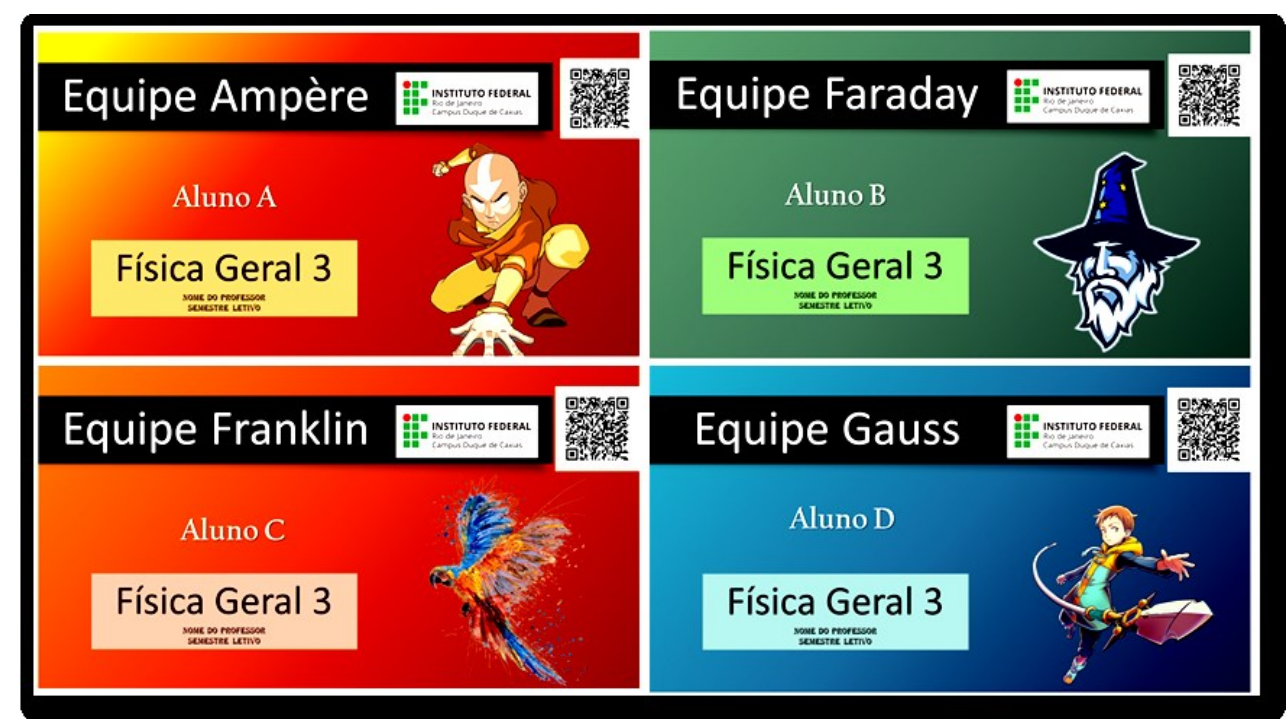

Fig. 1 - Cartões de avatar individuais para cada grupo. Fonte: Elaborado pelos autores.

As atividades foram divididas em categorias individuais (pontualidade e frequência), coletivas (lista de exercícios, seminários de aplicação) e competitivas (desafios entre equipes), que, ao serem concluídas, remuneravam os alunos com moedas do jogo denominadas "teslas" seguindo a distribuição apresentada no Quadro 1.

Em cada encontro um tópico do conteúdo programático era abordado e duas listas contendo os nomes dos alunos eram disponibilizadas para serem assinadas. A primeira, referente à pontualidade, que era retirada assim que o professor começasse a aula, e a segunda referente à frequência, que ficava disponível durante toda a primeira parte da aula e era retirada apenas após o intervalo. Recompensar a frequência e pontualidade por meio de teslas aumenta a participação dos alunos nas aulas, o que possibilita ao professor estimular a 
curiosidade por meio da apresentação de problemas relacionados ao assunto abordado e com isso conquistar a atenção do estudante para que se interesse pelo conteúdo.

Quadro 1 - Quantidade máxima de teslas obtidas em cada atividade realizada.

\begin{tabular}{|c|c|}
\hline ATIVIDADES & QUANTIDADE DE TESLAS \\
\hline Pontualidade & 10 \\
\hline Frequência & 10 \\
\hline Lista de exercícios & 30 \\
\hline Seminário de aplicação & 100 \\
\hline Desafios entre equipes & 30 \\
\hline
\end{tabular}

Fonte: Elaborado pelos autores.

Essa ação, na proposta de gamificação, representou o primeiro elemento do modelo ARCS, a atenção (KELLER, 2010). O segundo elemento do modelo ARCS, relevância, foi implementado nas atividades: lista de exercícios e seminário de aplicação. Segundo Keller (2010) a relevância está relacionada ao aumento da motivação e pode ser atingida por meio da combinação ou não de diferentes estratégias (experiência, mostrar que vale a pena, utilidade futura, congruência com o objetivo, exemplo, possibilidade de escolha).

Para a atividade lista de exercícios foi utilizada a estratégia de experiência seguindo a seguinte sequência: sempre que um tópico do conteúdo programático era finalizado, uma lista de exercícios era disponibilizada as equipes que deveriam entregar a lista resolvida no próximo encontro. As listas tinham o valor total de até trinta teslas que podiam variar para menos de acordo com o desempenho da equipe na resolução. Como os tópicos do conteúdo programático de Física Geral 3 estavam interligados em sequência, as habilidades desenvolvidas nos conteúdos anteriores serviam de base aos conteúdos futuros, característica da estratégia de experiência sinalizada por Keller (2010) quando diz que aprendemos melhor quando construímos novos conhecimentos sobre aqueles que já temos. Na atividade seminário de aplicação, cada equipe deveria pensar em tema de aplicação de algum fenômeno ou tecnologia presente no cotidiano dos alunos, que estivessem relacionados direta ou indiretamente ao conteúdo programático do curso, a ser ministrado para toda a turma em algum encontro antes das provas do semestre. $\mathrm{O}$ modelo proposto de estrutura do seminário e escolha do tema segue a combinação entre as estratégias de mostrar que vale a pena e utilidade futura de Keller (2010), visto que, a relevância é atingida, quando o aluno percebe como o objeto de estudo está relacionado a sua vida. As equipes ficaram responsáveis por agendarem e apresentarem durante o semestre dois seminários de aplicação, que abordaram assuntos como funcionamento de máquinas copiadoras, bússola, fogões por indução, trens com movimentação por levitação magnética e até mesmo o comportamento de movimentação das abelhas. O seminário de aplicação valia até cem teslas, avaliado pelo do docente. $\mathrm{O}$ 
terceiro elemento do modelo ARCS, confiança, foi vinculado à atividade competitiva de desafio entre equipes. Segundo Keller (2010) é importante o aluno saber que é capaz de aprender, identificar suas fragilidades e acreditar que possui as ferramentas necessárias para progredir em seu aprendizado. Nessa atividade, as equipes deveriam apresentar um desafio a outra equipe, apenas uma vez, que consistia em um problema relacionado aos conteúdos já abordados na disciplina a ser entregue na aula seguinte por meio da apresentação da solução para toda a turma em no máximo 20 minutos. Caso a equipe desafiada não conseguisse resolver o problema proposto à equipe desafiante teria a chance de solucioná-lo para a turma. A equipe que resolvesse o desafio ganharia trinta teslas. Ao término do desafio o professor dava seu feedback as equipes diferenciando os pontos do problema que ele julgasse já aprendidos e os ainda em desenvolvimento, na tentativa de mostrar aos alunos que a confiança em si mesmos é um processo em constante construção.

$\mathrm{O}$ último elemento do modelo ACRS, satisfação, foi aplicado às provas, que continham cinco questões discursivas, totalizando dez pontos (dois pontos por questão), divididas em níveis: duas questões bronze (questões de nível fácil baseadas no entendimento de conceitos), duas questões prata (questões de nível moderado em que conceitos eram relacionados a equações e suas aplicações) e uma questão ouro (questões de nível difícil em que diferentes conceitos eram relacionados a equações e/ou situações problemas contextualizadas). Os níveis de dificuldade são elementos importantes em um processo de gamificação, pois medem a evolução dos alunos e em que momento do aprendizado eles se encontram. Para Kapp, Blair e Mesch (2014) submeter aos alunos apenas a questões de baixa dificuldade pode gerar cansaço, ansiedade e tédio, enquanto apenas a questões com alta dificuldade, desânimo, frustração e desistência, por isso, advertem que deve haver equilíbrio entre os níveis de dificuldades o que eles denominam área de fluxo, um intervalo entre questões difíceis e fáceis que no fim do processo gera a sensação de satisfação ao concluir o objetivo.

O mercado, ambiente em que o aluno pode gastar suas teslas para adquirir os recursos que julgar necessários para realizar sua prova, é o grande marco da proposta de gamificação do processo avaliativo. Os itens foram criados de maneira a permitir certo grau de flexibilidade ao aluno na maneira de ser avaliado. O máximo de teslas que poderiam ser conquistadas pelos alunos eram trezentas e vinte, esse número foi calculado de maneira a manter o equilíbrio do nível de dificuldade previsto por Kapp, Blair e Mesch (2014), não havendo nem escassez nem excesso de oferta de possibilidades. Dessa forma, o mercado continha uma variedade de itens com custo estipulado conforme descrito no Quadro 2.

O item "prova em dupla" permitia a realização da avaliação por dois estudantes colaborativamente, desde que dois alunos gastassem suas teslas, ou seja, cada um necessitaria pagar o valor de 200 teslas. Os itens “+2", “+1" e " $+0,5$ " davam pontos bônus na prova. Era permitido aos alunos comprarem cada item do mercado apenas uma vez, entretanto o aluno que escolhesse comprar os itens " +2 " e "+1" começaria a prova com 3 pontos garantidos, o 
que geraria recálculo da pontuação geral de forma proporcional para cada questão (as questões passariam a valer sete pontos em vez de dez).

Quadro 2 - Itens do mercado.

\begin{tabular}{|c|c|}
\hline \multicolumn{2}{|c|}{ MERCADO } \\
\hline Item & Custo em Teslas \\
\hline+2 & 150 \\
\hline+1 & 100 \\
\hline$+0,5$ & 50 \\
\hline Anular Nível Prata & 100 \\
\hline Anular Nível Ouro & 150 \\
\hline Questão Alternativa & 30 \\
\hline Prova em Dupla & 200 \\
\hline Item oculto & 170 \\
\hline Doação de teslas & - \\
\hline
\end{tabular}

Fonte: Elaborado pelos autores.

Os itens "anular uma questão prata" ou "anular uma questão ouro" acarretavam a redistribuição da pontuação da questão anulada proporcionalmente entre as demais questões. O item "questão alternativa" dava ao aluno uma questão extra de nível bronze ou prata, cujo acesso ele só teria ao realizar a compra, permitindo maiores opções de escolha em seu processo avaliativo, já que esse item tinha custo reduzido. $\mathrm{O}$ item "compra única" era secreto e arriscado, disponível no mercado apenas para um aluno. Como na maioria dos jogos há um desafio, a gamificação do processo avaliativo não poderia ser diferente: a "compra única" resultava na possibilidade de anular a questão ouro e ficar com os pontos dela, sem distribuição proporcional. Era permitida ainda a doação de teslas entre os alunos, mas com regras e a um custo. Nenhum aluno poderia doar teslas sem antes ter esgotado suas possibilidades de compras no mercado e a doação de teslas tinha uma retenção de $25 \%$ do valor doado. Essas regras visavam manter o equilíbrio no processo de gamificação.

A Fig. 2 apresenta o ambiente do mercado criado para o processo de gamificação da avaliação. 


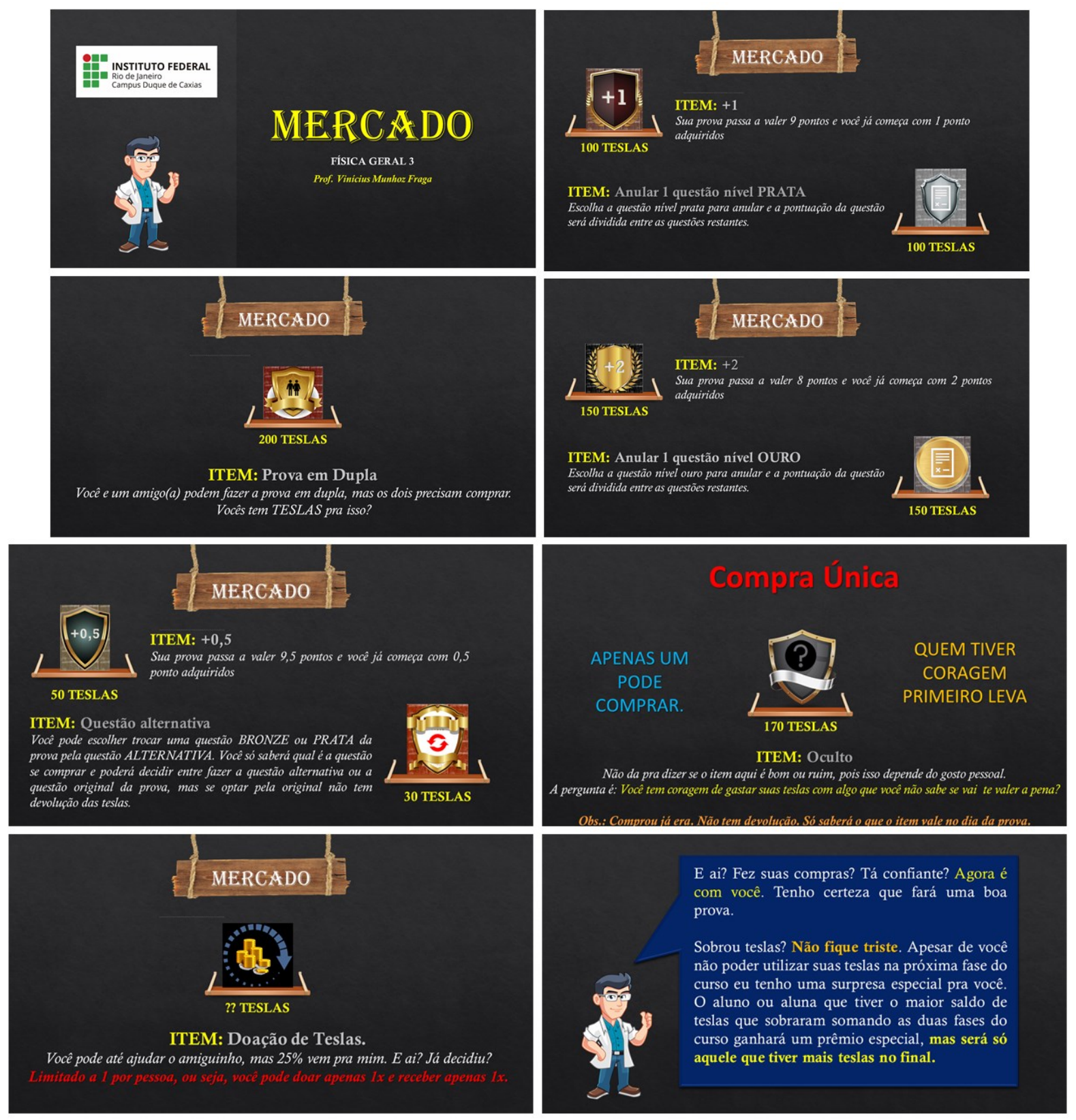

Fig. 2 - Mercado do processo de gamificação da avaliação. Fonte: Elaborado pelos autores.

\section{Resultados}

A coleta de dados se deu por meio de um questionário aberto, apresentado no Quadro 3, aplicado em formato digital fazendo uso do recurso gratuito de formulários do Google (Forms), cujas respostas das perguntas foram analisadas segundo a Análise de Livre Interpretação (ALI) de Anjos, Rôças e Pereira (2019). 
Quadro 3 - Questionário utilizado na coleta de dados.

\section{QUESTIONÁRIO}

Você já tinha tido alguma disciplina de forma gamificada? Se sim, comente se foi no nível superior ou nível médio.

Como aluno de licenciatura, algum professor já tinha apresentado a metodologia gamificação a vocês em algum momento do curso? Se sim, comente sobre as circunstâncias.

$\mathrm{Na}$ sua opinião, quais foram as vantagens de ter uma disciplina ministrada através da gamificação ou com elementos de gamificação?

$\mathrm{Na}$ sua opinião, quais foram as desvantagens de ter uma disciplina ministrada através da gamificação ou com elementos de gamificação?

O que você achou de todas as suas atividades valerem TESLAS (moeda do jogo) a serem utilizadas no mercado?

Sobre o mercado em si, qual sua visão acerta desse elemento de jogo presente na metodologia de gamificação aplicada no curso de Física Geral 3? Comente destacando possíveis pontos positivos e negativos.

Pelo que você esperava do curso de Física Geral 3, a metodologia de gamificação auxiliou ou não seu desenvolvimento na disciplina? Comente.

Como futuro professor, qual seu parecer geral sobre a metodologia de ensino gamificação?

Fonte: Elaborado pelos autores.

Em uma das questões, eles deveriam responder se já tinham tido contato com a gamificação. Nenhum dos estudantes passou por qualquer experiência nesse sentido, e dois afirmaram ter ouvido sobre a metodologia em duas disciplinas cursadas anteriormente. Sabendo que os participantes da pesquisa são alunos de licenciatura essas respostas corroboram Bacich e Moran (2018) quando abordam o excesso de publicações sobre metodologias ativas, mas a pouca prática efetiva nas escolas.

Em relação às vantagens e desvantagens acerca da metodologia proposta, destacamos as respostas de alguns estudantes:

Poder montar uma estratégia personalizada na hora de fazer a prova com os teslas e o mercado. (Aluno 2)

Essa metodologia faz com que os alunos, principalmente quem gosta de games, se interessar mais pela disciplina. Também proporciona a possibilidade de que o aluno trace estratégias próprias para o seu desenvolvimento. (Aluno 3) 
Poder ter a justiça de não ser avaliado exclusivamente por prova. Indiretamente ganhar teslas era uma forma de avaliação. (Aluno 7)

Tornou a disciplina mais descontraída e deu mais liberdade na composição da nota. (Aluno 8)

Serve como um estímulo a mais para o aprendizado e deixa a aula mais descontraída. (Aluno 10)

Os elementos da gamificação ajudaram a criar e manter o interesse na disciplina, pois dava uma quebrada na metodologia tradicional que geralmente é utilizado pelos docentes da disciplina, fugindo da monotonia. (Aluno 11)

Um incentivo em certos pontos (que deveriam ser obrigação) como a pontualidade. Mas incentivo também a fazer trabalhos já que eram opcionais. Não prejudicava diretamente, era o aluno com sua consciência de fazer ou não. (Aluno 13)

Alguns alunos mencionaram a flexibilidade proporcionada pela gamificação, fator destacado por Kapp, Blair e Mesch (2014) quando diz que a gamificação permite ao professor atender a necessidades específicas dos estudantes, como evidenciam as falas dos Alunos 2, $3 \mathrm{e}$ 8 acima. A fala do Aluno 7 revela sua visão sobre uma avaliação contínua em que as teslas representavam seu esforço e dedicação, tendo a prova apenas como culminância do processo avaliativo. Já os Alunos 10, 11 e 13 destacaram o engajamento proporcionado pela gamificação com o aumento de interesse pela disciplina, característica essa enfatizada por vários autores na literatura (KAPP; BLAIR; MESCH, 2014; MATTAR, 2017; BACICH; MORAN, 2018). Destacam-se ainda, nessas falas, fatores apresentados por Alves (2015) como motivação, imersão nas tarefas, estímulo à competitividade e dinamismo nas aulas todos considerados como vantagens pelos estudantes.

Em se tratando das desvantagens, oito alunos não destacaram nenhuma, revelando impacto positivo, mas também certa empolgação. Ainda assim, alguns alunos relataram dificuldades de se ambientar com propostas diferentes daquelas tradicionalmente usadas. Nesse sentido, Alves (2015) menciona que a gamificação não pode ser vista apenas como entretenimento, já que o objetivo final é a aprendizagem. No entanto, é natural que alunos acostumados com o ensino tradicional apresentem certa resistência ao se deparar com algo que o retire de sua zona de conforto. Também foi indicado por um aluno o árduo trabalho demandado para o professor ao desenvolver e aplicar a gamificação em suas aulas. Esses aspectos encontram-se exemplificados nas respostas a seguir.

Pra mim nenhuma, mas pra quem não entende o mundo dos games é bem difíil de entender. (Aluno 4)

Como não tenho o costume de jogar, acabei errando algumas vezes na estratégia. (Aluno 6) 
Achei ruim o fato de existir apenas elementos de gamificação contrastando com as aulas tradicionais. (Aluno 8)

Desvantagem total para o professor. Pois ele fica com a parte trabalhosa. (Aluno 10)

Ao analisar especificamente a gamificação do processo avaliativo, de forma geral, os alunos se sentiram motivados a participar das aulas e a realizarem as atividades em troca de teslas. Isso demonstra o potencial da metodologia da gamificação descrita por Kapp, Blair e Mesch (2014) em promover engajamento e motivação nos alunos.

Eu particularmente gostei muito, por não conhecer como funcionava uma disciplina gamificada, achei super original a ideia da moeda de troca. (Aluno 1)

Achei bom, pois permitia personalizar uma estratégia na hora de fazer a prova, mas as vezes parecia frustrante pois como os teslas não são pontos, as vezes parecia que estava fazendo as atividades por nada. Mas no geral, foi bom. (Aluno 2)

Uma excelente ideia, pois ela que fez com que os alunos traçassem suas estratégias. (Aluno 3)

Achei bastante justo. Porém não difere tanto do modelo tradicional onde as atividades valem pontos que irão compor a nota. (Aluno 8)

Achei mega divertido, pois tirou um pouco a tensão da dificuldade que a matéria proporciona. (Aluno 9)

Isso refletiu diretamente no comportamento da turma. Buscando chegar no horário, não faltar, fazendo seminários e fazendo as atividades. (Aluno 10)

Muito útil, pois me ajudou a ter beneficios na prova fazendo com que eu não ficasse nervoso/ansioso por causa das avaliações. (Aluno 11)

Um modo diferenciado pra fazer com que haja um interesse maior em fazer as atividades propostas. (Aluno 15)

Para o Aluno 1, a originalidade da ideia reforça positivamente seu primeiro contato com a metodologia. Para um aluno de licenciatura, futuro professor, é imprescindível conhecer as potencialidades de novas metodologias de ensino. Já os alunos 2 e 3 destacaram novamente a possibilidade de se criar novas estratégias em sua avaliação com a utilização das teslas, entretanto o Aluno 2 relata certa frustração ao entender que as atividades propostas eram feitas sem ter nenhum valor de nota agregado de forma imediata, novamente remetendo à Alves (2015) acerca da possibilidade de resistência dos alunos a novas metodologias, o que evidencia possíveis barreiras encontradas pelos docentes ao integrarem novas metodologias de ensino a 
sua práxis. Alguns alunos, condicionados ao formato tradicional de avaliação, se sentem desnorteados quando surgem novas propostas. Isso se confirma na fala do Aluno 8 ao comparar as teslas aos pontos adquiridos em uma disciplina tradicional. No entanto, fatores apresentados por Kapp, Blair e Mesch (2014) e reforçados por Alves (2015) e Mattar (2017), como diversificação das atividades, flexibilidade nas estratégias de avaliação, engajamento e motivação não existem nas falas de alunos que comparam novas metodologias às antigas. Isso demonstra o despreparo de futuros professores em entender benefícios trazidos por novas metodologias, desafios a serem superados tanto por docentes quantos por discentes.

Os Alunos 9 e 11 destacaram a diversão como característica da gamificação. Mesmo não sendo o objetivo final dessa proposta, a diversão, permite um ambiente mais agradável, diminuindo a tensão da formalidade acadêmica e aumentando a motivação (KAPP; BLAIR; MESCH, 2014; BURKE, 2015; ALVES, 2015). Já os Alunos 10 e 15 mencionaram o aumento de interesse por uma disciplina geralmente complexa e abstrata - suas falas evidenciaram a afirmação de Kapp, Blair e Mesch (2014) de que o aumento de interesse provocado pela gamificação promove o aumento do engajamento, característica que tem impacto direto no processo de aprendizagem. A maioria dos alunos se sentiu motivada a conquistar teslas, o que a engajou a realizar as atividades propostas, inclusive aquelas às quais já estava habituada a realizar em uma metodologia tradicional de ensino.

Em relação ao mercado, as falas dos Alunos 5, 7 e 12 resumem os principais pontos a serem melhorados, destacados pelos alunos. Apesar de ser uma proposta piloto, a gamificação desenvolvida no processo avaliativo permitia várias possibilidades de itens de mercado, sendo limitado apenas pela criatividade de quem os propõem. O processo de gamificação utiliza elementos de jogos e, de fato, todos os jogos permitem ao jogador novas tentativas (KAPP; BLAIR; MESCH, 2014; ALVES, 2015), para que o aprendizado com seus erros seja repensado e novas atitudes sejam tomadas, o que contrasta com a fala do Aluno 12 ao sinalizar seu medo de realizar a escolha errada na hora de adquirir itens do mercado. Isso evidencia que a proposta apresentada ainda pode ser melhorada em vários aspectos, como exemplo, a possibilidade de refazer suas escolhas com base nos erros anteriormente cometidos. Já no tocante aos pontos positivos, a maioria dos alunos destacou o elemento flexibilidade (KAPP; BLAIR; MESCH, 2014; BURKE, 2015; ALVES, 2015) da avaliação como principal ponto positivo. Isso fica claro na fala dos Alunos 1, 2, 5 e 8.

Respeitar características individuais e a evolução de cada estudante foi um ponto de destaque da avaliação baseada na gamificação com a personalização do processo. Esses aspectos encontram-se exemplificados nas falas a seguir.

Não sei se, a meu ver, tem pontos negativos. Achei interessantes os itens e nos faz pensar em diversas estratégias pra ter um resultado satisfatório. (Aluno 1) 
Os pontos positivos eram de que o mercado era bem diverso, poderia comprar pontos, anular questões, montar a melhor estratégia pra você.... Não vejo pontos negativos no mercado. (Aluno 2)

Assim como as teslas, o mercado nos possibilitava com base nos ganhos durante o periodo, montarmos a melhor estratégia individual para as provas. Como ponto negativo, acredito que o fato do mercado ser direcionado especificamente para as provas, limitou-se as possibilidades do seu uso. (Aluno 5)

Poderiam existir mais itens e opções de compras. (Aluno 7)

Eu achei interessante pois dava ao aluno autonomia para escolher a forma como melhor seria avaliado. Cada um poderia realizar a estratégia que fosse mais vantajosa. (Aluno 8)

O único ponto negativo é o receio de fazer a escolha errada e não poder voltar atrás. Os pontos positivos são a facilidade e a tranquilidade gerada durante a prova. (Aluno 12)

São elementos de interessantes a serem comprados que fazem com que a prova se torne mais divertida. (Aluno 15)

A ideia desenvolvida nesse artigo não foi comparar metodologias tradicionais e metodologias consideradas modernas, mas apresentar uma proposta de gamificação do processo avaliativo. Nesse sentido, as falas dos Alunos 1 e 6 destacaram o incentivo do professor nas aulas como algo que cativou sua motivação. De fato, toda metodologia ativa exige um papel diferenciado do docente (MORAN, 2015), seja na discussão acerca de conteúdo, na mediação de debates ou na curadoria da turma em conjunto com a metodologia o papel do professor sempre terá seu destaque. Já os Alunos 2, 5, 6 e 12 destacaram o fator de engajamento adquirido por meio da gamificação. A responsabilidade com assiduidade e pontualidade, participação em grupo e aumento de interesse nas aulas foram características que demonstraram o aumento do engajamento da turma no processo de aprendizagem. $O$ fator conteudista e expositivo de uma aula tradicional foi destacado pelos alunos 6 e 8 . De fato, apesar do carisma do professor e de sua tentativa em dinamizar as aulas expositivas, elas não tiveram os mesmos elementos de jogos inseridos no processo avaliativo. Como se tratava de uma turma de licenciatura, as discussões sobre metodologias de ensino sempre existiram, mas como é impossível desvincular as aulas do processo avaliativo, o professor-pesquisador entende que a fala desses alunos representam sua vontade de aulas mais atrativas quando se abordam assuntos abstratos como os das ciências da natureza, em especial a física. As falas a seguir exemplificam esses aspectos.

Acho que não sei responder essa com exatidão, porque eu não sei se foi a própria gamificação ou todo o incentivo do professor e do grupo, que foram decisivos para chegar até o término da disciplina. (Aluno 1) 
Apesar de ser uma metodologia muito legal e que estimula a sempre se manter em dia com as atividades, fazer o aluno chegar cedo e não faltar, pro meu caso, achei que não ajudou muito. Mesmo com a metodologia, eu tive muitas dificuldades, as mesmas que teria com uma metodologia puramente tradicional. (Aluno 2)

Auxiliou, pois com a possibilidade do ganho das teslas, aumentou o interesse em fazer as atividades e participar das aulas, pois tudo o que estava sendo feito poderia estar valendo algo. (Aluno 5)

Sim. Mas a matéria é complexa e embora a metodologia estimulasse a participação nas aulas e o professor tivesse um bom relacionamento com a turma, as aulas ainda não eram motivadoras. (Aluno 6)

Não, a metodologia tornou a disciplina mais agradável, mas não teve impacto no meu aprendizado. As aulas ainda tinham um teor conteudista e bastante expositivo. (Aluno 8)

É uma disciplina que tenho muita dificuldade. Mas a possibilidade de outras formas de avaliação além de teste e prova me manteve motivado. (Aluno 10)

Auxiliou, porque me incentivou a estar presente nas atividades do meu grupo. (Aluno 12)

A gamificação não me auxiliou a aprender melhor a matéria. A tornou mais divertida, mas não teve um real auxílio para mim. (Aluno 15)

$\mathrm{Na}$ última questão do questionário, buscou-se identificar a visão de futuros docentes acerca da metodologia que lhes tinha sido apresentada. Praticamente todos os estudantes destacaram o fator motivação e engajamento como predominante na metodologia de gamificação. Eles se sentiram motivados a participar das aulas, a se envolverem nas atividades, a se manterem comprometidos com sua frequência e pontualidade - características que a gamificação permite ao ser utilizada como metodologia de ensino (KAPP; BLAIR; MESCH, 2014; BURKE, 2015; ALVES, 2015). Apesar de ser uma metodologia com potencial de desenvolver o fator engajador e motivacional, ela demanda planejamento e compromisso do educador. O interesse é potencializado a partir da gamificação, mesmo quando aplicada apenas no processo avaliativo. As respostas dos estudantes que exemplificam isso se encontram expostas a seguir.

Que eu não sei se teria coragem de fazê-la. Eu realmente gostei e muito dessa metodologia, porém a mesma exige muito planejamento e não sei se teria esse tempo no futuro, devido às condições atuais no mercado de trabalho. Porém, caso algum dia eu tenha a condição de preparar algo parecido, nem que seja uma aula apenas, farei. (Aluno 1) 
É uma metodologia bem válida, pois foge da metodologia totalmente tradicional que as vezes faz com que o aluno não tenha o menor interesse pela matéria. Com uma metodologia gamificada, pode trazer a atenção e o interesse do aluno pela matéria, o que é muito útil. (Aluno 2)

O uso da gamificação com certeza auxilia no aprendizado e interesse dos alunos em relação a disciplina, ainda mais sendo esta disciplina, tão criticada por ser maçante e desgostosa. (Aluno 5)

A metodologia pareceu demandar bastante trabalho pro professor, assim como para os alunos. Porém, a forma de utilização da metodologia fez com que eu me esforçasse para chegar cedo na aula e me empenhasse mais em fazer as atividades. Acredito que faltam alguns ajustes para acabar melhor a metodologia e a forma de ministrar a aula, para que ambas se tornem atrativas juntas. Mas a presença em sala de aula foi visivelmente afetada (positivamente) pela gamificação. (Aluno 6)

É uma ferramenta de grande potencial embora requeira muito planejamento e trabalho para ser bem implantada. (Aluno 10)

Uma excelente ferramenta pedagógica que coloca o aluno como protagonista e o incentiva a participar de tudo. (Aluno 12)

É uma metodologia valida pra qualquer matéria, visto que a condição de aprendizagem do aluno ainda é o fator mais importante para a aprovação ou não do aluno. (Aluno 15)

Destaca-se, por fim, a fala do Aluno 15 ao sinalizar que como a gamificação é uma metodologia de ensino, ela pode ser adaptada a qualquer disciplina do currículo escolar, cabendo ao docente a tarefa de planejar a maneira mais adequada.

\section{Considerações finais}

A proposta de combinação entre metodologia passiva e ativa foi apresentada como uma alternativa a professores que ainda enfrentam dificuldades num sistema educacional pouco flexível. A implementação da proposta de gamificação da disciplina de Física Geral 3 em um curso de Licenciatura combinada ao modelo ARCS se mostrou eficiente, pois apesar de ter sido aplicada apenas ao processo avaliativo, possibilitou o aumento do engajamento e da motivação dos alunos, que destacaram uma disciplina divertida e agradável, com nível de dificuldade balanceado, o que facilitou para que se mantivessem interessados por mais tempo no curso.

Tendo em vista que os participantes eram licenciandos, ou seja, futuros professores, o aprendizado foi além do proposto originalmente. A apresentação da metodologia ativa com a gamificação aplicada durante todo um semestre letivo e desenvolvida paralelamente à metodologia passiva permitiu que eles refletissem não somente sobre seu processo de ensinoaprendizagem como também sobre os desafios e a prática pedagógica de um docente. 
Entendemos que a metodologia de gamificação tem muito a contribuir no processo de formação dos alunos do século XXI e necessita de novas propostas práticas que cheguem de fato à sala de aula. Numa perspectiva futura, buscaremos desenvolver um curso totalmente gamificado (processo didático e processo avaliativo), além de investigar outras estratégias de gamificação e suas implicações no processo de aprendizagem dos alunos.

\section{Agradecimento}

Aos pareceristas, pelas contribuições fundamentais dadas a este artigo.

Às instituições que financiam as pesquisas dos autores: Instituto Federal do Rio de Janeiro (IFRJ); Fundação Carlos Chagas Filho de Amparo à Pesquisa do Estado do Rio de Janeiro (FAPERJ); Conselho Nacional de Desenvolvimento Científico e Tecnológico (CNPq).

\section{Referências}

ALVES, F. Gamification: como criar experiências de aprendizagem engajadoras. Um guia completo: do conceito a prática. 2. ed. São Paulo: DVS, 2015.

ANJOS, M. B. dos; RÔÇAS, G.; PEREIRA, M. V. Análise de livre interpretação como uma possibilidade de caminho metodológico. Ensino, Saúde e Ambiente, v. 12, n. 3, p. 27-39, 2019. Disponível em: <https://periodicos.uff.br/ensinosaudeambiente/article/view/29108>. Acesso em: 21 jul. 2020.

BACICH, L.; MORAN, J. Metodologias ativas para uma educação inovadora: uma abordagem teórico-prática. Porto Alegre: Penso, 2018.

BLOOM, B. S.; HASTING, T.; MADAUS, G. Manual de avaliação formativa e somativa do aprendizado escolar. São Paulo: Editora Pioneira, 1983.

BURKE, B. Gamificar: como a gamificação motiva as pessoas a fazerem coisas extraordinárias. São Paulo: DVS, 2015.

CAMARGO, F.; DAROS, T. A sala de aula inovadora: estratégias pedagógicas para fomentar o aprendizado ativo. Porto Alegre: Penso, 2018.

FAVA, R. Educação 3.0. São Paulo: Saraiva, 2014.

JARAUTA, B.; IMBERNÓN, F. Pensando no futuro da educação: uma nova escola para o século XXI. Porto Alegre: Penso, 2015. 
KAPP, K. M.; BLAIR, L.; MESCH, R. The gamification of learning and instruction fieldbook: ideas into practice. San Francisco: Wiley, 2014.

KELLER, J. M. Motivational design for learning and performance: the ARCS model approach. New York: Springer, 2010.

MATTAR, J. Metodologias Ativas: para a educação presencial, blended e a distância. São Paulo: Artesanato Educacional, 2017.

MORAN, J. Mudando a educação com metodologias ativas. In: SOUZA, C. A. de; MORALES, O. E. T. (Org.). Convergências Midiáticas, Educação e Cidadania: aproximações jovens. Ponta Grossa: UEPG/PROEX, 2015. p. 15-33. Disponível em: $<$ http://rh.unis.edu.br/wp-content/uploads/sites/67/2016/06/Mudando-a-Educacao-comMetodologias-Ativas.pdf $>$. Acesso em: 21 jul. 2020. (Coleção Mídias Contemporâneas, 2) MOREIRA, M. A.; MASINI, E. F. S. Aprendizagem Significativa: a teoria de David Ausubel. 2. ed. São Paulo: Centauro, 2006.

PERRENOUD, P. Avaliação: da excelência à regulação das aprendizagens - entre duas lógicas. Porto Alegre: Artmed, 1999. 